\title{
Blood parameters, symptoms at presentation and adverse in-hospital outcomes of COVID-19 pneumonia in patients with hypertension
}

\author{
Foaad Shaghee', Hussein Nafakhi', Karrar Al-Buthabhak', Mohammed Alareedh², \\ Ahmed Nafakhi', Samet Kasim² \\ ${ }^{1}$ Faculty of Medicine, Jabir ibn Hayyan Medical University, Kufa, Najaf, Iraq \\ ${ }^{2}$ Internal medicine, Medicine College, University of Kufa, Najaf, Iraq \\ ${ }^{3}$ Research Unit, Najaf Health Bureau, Ministry of Health, Iraq
}

\begin{abstract}
Background: We aimed to explore the association of clinical symptoms of COVID-19 pneumonia, blood parameters on admission, and anti-hypertensive drugs with in-hospital outcomes, including length of hospital and intensive care unit (ICU) stay, receiving mechanical ventilation, degree of lung injury, and in-hospital death among patients with hypertension.

Material and methods: This retrospective study conducted in patients with newly diagnosed COVID-19 pneumonia from August 20, 2020 to September 25, 2020.

Results: A total of 182 patients with COVID-19 pneumonia were included in the present study. The patients were categorized into those with hypertension $(n=82)$ or without hypertension $(n=100)$. Patients on angiotensin receptor blockers (ARBs) and angiotensin-converting enzyme inhibitors (ACEIs) showed no significant increase in the risk for all in-hospital outcomes. Old age [0.6 $(0.5-2) \mathrm{p}<0.00]$, fever [0.3 $(0.2-1.8), \mathrm{p}<0.00]$ and low lymphocytes percentage $[0.3(0.2-1.2), \mathrm{p}<0.00]$ were associated with increased risk for extensive lung injury. Old age $[0.4(0.1=0.7) \mathrm{p}<0.01]$, high neutrophil count $[0.3(0.2-2), \mathrm{p}=0.02]$ and low lymphocyte percentage $[0.3(0.1-0.7), p=0.01]$ were associated with prolonged hospital stay while low lymphocytes percentage $[0.7(0.6-0.9)$, $\mathrm{p}<0.00]$, old age $[1.2(1-1.4), \mathrm{p}=0.01]$ and fatigue $[2(1-4), \mathrm{p}=0.04]$ showed significant association with prolonged length of ICU stay. Low lymphocytes percentage [0.7 $(0.6-1), \mathrm{p}<0.00]$, old age [1.1 $(1-1.2), \mathrm{p}=0.01]$ and fatigue [2 (1.7-4), $\mathrm{p}=0.02$ ] were associated with increased risk for receiving mechanical ventilation. Risk for in-hospital death was associated with increased neutrophil percentage [1.2 (1-1.5), $\mathrm{p}=0.01]$ and old age [1.1 $(1-1.2), \mathrm{p}=0.03$ ]. Conclusions: ARBs and ACEIs showed no significant association with adverse in-hospital outcomes. Old age, low lymphocytes percentage and high neutrophils percentage on admission were independent predictors for increased risk of in-hospital mortality and morbidity among COVID-19 pneumonia patients with hypertension.
\end{abstract}

Key words: COVID-19; blood parameters; hypertension; in-hospital outcome

Arterial Hypertens. 2021, vol. 25, no. 1, pages: 7-13 DOI: $10.5603 /$ AH.a2021.0004

Address for correspondence: Hussein Nafakhi, Internal medicine, Medicine College, University of Kufa, 5400-1 Najaf, Iraq, tel: 00964-7802184116; e-mail: husseinaf.alnaffakh@uokufa.edu.iq

This article is available in open access under Creative Common Attribution-Non-Commercial-No Derivatives 4.0 International (CC BY-NC-ND 4.0) license, allowing to download articles and share them with others as long as they credit the authors and the publisher, but without permission to change them in any way or use them commercially

VM Copyright (C) 2021 Via Medica, ISSN 2449-6170, e-ISSN 2449-6162 


\section{Introduction}

Severe acute respiratory syndrome coronavirus 2 (SARS-CoV2), was identified as the cause of an outbreak of acute respiratory illness in Wuhan City, China. The World Health Organization (WHO) declared that the SARS CoV-2 causes the $\mathrm{CoV}$ disease 2019 abbreviated as COVID-19 [1,2]. The severity of the COVID-19 infection can vary from patient to patient. Some cases of COVID-19 infection were associated with pneumonia and shortness of breath. On the other hand, some patients developed respiratory failure, septic shock, or multiple organ failure leading to death [2-4].

Previous clinical studies and reports on SARS and Middle East respiratory syndrome found that hypertension is associated with increased rate of morbidity and mortality in infected patients $[5,6]$.

Emerging data about COVID-19 pandemic reports that the morbidity and mortality rates of $\mathrm{CO}$ VID-19 infection in patients with cardiovascular diseases, including hypertension, are much higher than those of patients without comorbidities [7, 8]. The available evidence has suggested that COVID-19 severity and prognosis are significantly associated with cardiovascular disorders, but the specific mechanisms and link between the two are unclear [8]. Some initial reports have suggested that hypertension or its treatment may be involved in the pathogenesis and progression of COVID-19 due to interaction between SARS-COV-2 and angiotensin-converting enzyme 2 (ACE2), a potential receptor for SARSCOV-2 to enter human cells $[2,9]$. However, the potential effects of hypertension and its treatment on COVID-19 pneumonia severity and prognosis remain an area for active research. Also, there is limited evidence that determines the predictors of poor outcomes among COVID-19 pneumonia patients with hypertension during in-hospital course.

The main aim of the present study was to explore the association of clinical symptoms of COVID-19 pneumonia, blood parameters on admission, and anti-hypertensive drugs with in-hospital adverse outcomes, including length of hospital and intensive care unit (ICU) stay, receiving mechanical ventilation, degree of lung injury, and in-hospital death among patients with hypertension.

\section{Material and methods}

In this retrospective study, we recruited patients with newly diagnosed COVID-19 infection who presented with features suggestive of pneumonia to the
$\mathrm{Al}-\mathrm{Sader}$ teaching hospital in Al-Najaf governorate from August 20, 2020 to September 25, 2020. All patients were presented with features consistent with COVID-19 pneumonia based on clinical symptoms (fever, dry or productive cough, fatigue, or shortness of breath) and radiological findings. Diagnosis of COVID-19 infection was based on positive nasopharyngeal swab by real time polymerase chain reaction (PCR). At hospital admission, the baseline clinical characteristics and complete blood count were recorded using medical records and collected by attending physicians. The baseline clinical characteristics including age, sex, hypertension, diabetes mellitus, smoking, body mass index (BMI), previous coronary artery disease, anti-hypertensive drugs, complete blood count, and in-hospital clinical outcome. Complete blood parameters included white blood cell count (WBC), lymphocyte count and percentage, neutrophil count and percentage, red blood cell count (RBC), hemoglobin $(\mathrm{Hb})$, red blood cell mean volume $(\mathrm{MCV})$, red blood cell width distribution (RDW), platelet count, platelet distribution width (PDW), and platelet mean volume (PMV). Patients who were receiving antihypertensive therapy with the diagnosis of hypertension at the time of hospital admission were labeled as patients with hypertension. The severity of lung injury by COVID-19 pneumonia was assessed by CT scan examination score at the time of hospital admission. Patients were followed up in hospital until discharged or died. The main in-hospital outcome for the study was defined as receiving mechanical ventilation, length of hospital and ICU stay, degree of lung injury according to CT score and in-hospital death. Approval of this study was provided by our medicine College Board.

\section{Statistical analysis}

Statistical analysis was performed using SPSS ver. 23.0 (SPSS Inc., Chicago, IL, USA). P-value of $<0.05$ was chosen for statistical significance. Baseline clinical data of the patients and blood parameters were expressed as mean \pm standard deviation for continuous variables and compared by Student t-test or as numbers with percentages for categorical data and compared by chi-square test. Univariate analysis was used to calculate the odds ratio and confidence intervals [OR (CI)] and assess the association of anti-hypertensive drugs with in-hospital outcomes. Baseline clinical characteristics, including age, sex, diabetes mellitus, smoking, body mass index (BMI), previous coronary artery disease, clinical symptoms on admission and complete blood parameters underwent univariable logistic regression to the in-hospital outcomes. Those with a $\mathrm{p}$ value of $<0.05$ were found 
eligible for inclusion in the final multivariable logistic regression analysis to assess their independent association with in-hospital outcome.

\section{Results}

A total of 182 patients with COVID-19 pneumonia were included in the present study. The patients were categorized into those with hypertension [age (years) $58 \pm 9,33(40 \%)$ were males] or without hypertension [age (years) $42 \pm 15$, 49 (49\%) were males). In patients with hypertension, fever was the most common clinical symptom followed by dry cough, shortness of breath, fatigue, productive cough, taste and smell loss. Thirty nine (48\%) patients with hypertension were on angiotensin receptor blockers (ARBs) while 18 (22\%) patients were on angiotensin-converting enzyme inhibitors (ACEIs). Patients' characteristics are shown in Table 1.

Patients with hypertension were older (58 year versus 42 year, $\mathrm{p}<0.00)$ and had higher BMI values $(30$ versus $28, p=0.01)$ than patients without hypertension. The prevalence of diabetes mellitus $(\mathrm{p}<0.00)$, smoking $(\mathrm{p}=0.02)$, coronary artery disease $(\mathrm{p}<0.00)$ was higher among patients with hypertension compared to patients without hypertension. Shortness of breath $(\mathrm{p}<0.00)$ and loss of smell and taste $(\mathrm{p}<0.00)$ were more frequently observed among patients with hypertension while no significant change in the frequency of fever, dry and productive cough, and fatigue between the groups with and without hypertension. Regarding blood parameters distribution, higher values of white blood cells (1000 vs. 8000, $\mathrm{p}=0.03)$, neutrophil count (8000 vs. 5000, $\mathrm{p}<0.00$ ), neutrophil percentage (77 vs. $62, \mathrm{p}<0.00)$, and PDW (13 vs. $12, \mathrm{p}=0.01$ ) and lower values of lymphocyte count (1.4 vs. 2.3, $\mathrm{p}<0.00)$ and lymphocytes percentage (16 vs. 29 , $\mathrm{p}<0.00)$ were observed among patients with hypertension compared to patients without hypertension. With the exception of in-hospital death, the remaining in-hospital outcomes, including length of hospital and ICU stay, receiving mechanical ventilation, and lung injury were more common in patients with hypertension than patients without hypertension $(\mathrm{p}<0.00)($ Tab. 1).

\section{Predictors of in-hospital outcome among patients with hypertension}

Patients on ARBs and ACEIs showed no significant increase in the risk for all in-hospital outcomes in univariate analysis (Tab. 2) Baseline clinical symptoms, comorbidities and blood parameters which were significant in univariate analysis were selected for final multivariate analysis.

Old age [0.6 (0.5-2), $\mathrm{p}<0.00]$, fever [0.3 (0.2-1.8), $\mathrm{p}<0.00]$ and low lymphocyte percentage $[0.3$ $(0.2-1.2), \mathrm{p}<0.00]$ were associated with increased risk for extensive lung injury as assessed by CT scan examination. Old age [0.4 (0.1-0.7), $\mathrm{p}<0.01]$, increased neutrophil count $[0.3(0.2-2), \mathrm{p}=0.02]$ and low lymphocyte percentage [0.3 $(0.1-0.7), \mathrm{p}=0.01$ ] were associated with prolonged hospital stay while low lymphocyte percentage [0.7 (0.6-0.9), $\mathrm{p}<0.00]$, old age [1.2 (1-1.4), $\mathrm{p}=0.01]$ and fatigue [2 (1-4), $\mathrm{p}=0.04]$ showed significant association with prolonged length of ICU stay. Low lymphocyte percentage $[0.7(0.6-1), \mathrm{p}<0.00]$, old age $[1.1(1-1.2)$, $\mathrm{p}=0.01]$ and fatigue $[2(1.7-4), \mathrm{p}=0.02]$ were associated with increased risk for receiving mechanical ventilation. Risk for in-hospital death was associated with increased neutrophil percentage [1.2 (1-1.5), $\mathrm{p}=0.01]$ and old age [1.1 (1-1.2), $\mathrm{p}=0.03]$.

\section{Discussion}

The major findings of our study were: (1) comparative analysis of COVID-19 pneumonia patients with and without hypertension showed that patients with hypertension had higher prevalence of age $>45$ year, obesity, diabetes mellitus, history of coronary artery disease, and smoking than patients without hypertension; (2) in-hospital outcomes, including length of hospital and ICU stay, receiving mechanical ventilation, and lung injury were more common in patients with hypertension than patients without hypertension $(\mathrm{p}<0.00)$; (3) ARBs and ACEIs were not associated with increased risk of adverse in-hospital outcome; (4) old age, low lymphocyte percentage, and high neutrophil count and percentage were associated with increased risk for adverse in-hospital outcome among patients with hypertension.

During the previous outbreak of Middle East Respiratory Syndrome (MERS), Metabolic disorders and clinical predictors of morbidity and mortality outcomes among MERS-CoV infected patients were hypertension, old age, diabetes, obesity, and coronary artery disease. These comorbidities can be involved or linked etiologically to the pathogenesis of MERS-CoV through modulating the innate immune response of the host $[1,10,11]$.

According to data from china, COVID-19 patients with metabolic disorders showed adverse clinical outcome $[2,12]$. It is speculated that systemic inflammation may be the major factor for development and progression of COVID-19. Several studies 
Table 1. Patients characteristics

\begin{tabular}{|c|c|c|c|}
\hline Variables & $\begin{array}{l}\text { Hypertension } \\
(\mathrm{n}=\mathbf{8 2})\end{array}$ & $\begin{array}{l}\text { Without hypertension } \\
\qquad(\mathrm{n}=100)\end{array}$ & p value \\
\hline Age (years) & $58 \pm 9$ & $42 \pm 15$ & $<0.00$ \\
\hline Male sex, n (\%) & $33(40 \%)$ & $49(49 \%)$ & 0.23 \\
\hline Diabetes mellitus, $\mathrm{n}(\%)$ & $41(50 \%)$ & $19(19 \%)$ & $<0.00$ \\
\hline Smoking & $20(24 \%)$ & $12(12 \%)$ & 0.02 \\
\hline Coronary artery disease, $\mathrm{n}(\%)$ & $19(23 \%)$ & $4(4 \%)$ & $<0.00$ \\
\hline $\mathrm{BMI}$ & $30 \pm 5$ & $28 \pm 4$ & 0.01 \\
\hline Fever, n (\%) & $70(85 \%)$ & $82(82 \%)$ & 0.54 \\
\hline Dry cough, $\mathrm{n}(\%)$ & $63(77 \%)$ & $75(75 \%)$ & 0.77 \\
\hline Productive cough, n (\%) & $23(28 \%)$ & $24(24 \%)$ & 0.53 \\
\hline Smell loss, n (\%) & $14(17 \%)$ & $43(43 \%)$ & $<0.00$ \\
\hline Taste loss, n (\%) & $18(22 \%)$ & $45(45 \%)$ & $<0.00$ \\
\hline Fatigue, $\mathrm{n}(\%)$ & $37(45 \%)$ & $45(45 \%)$ & 0.98 \\
\hline Shortness of breath, $n(\%)$ & $56(68 \%)$ & $47(47 \%)$ & $<0.00$ \\
\hline \multicolumn{4}{|l|}{ Anti-hypertension drugs } \\
\hline ARBs, $n(\%)$ & $39(48 \%)$ & - & - \\
\hline ACEls, $n(\%)$ & $18(22 \%)$ & - & - \\
\hline Ca channel blockers, $n(\%)$ & $18(22 \%)$ & - & - \\
\hline Beta-blockers, $\mathrm{n}(\%)$ & $8(10 \%)$ & - & - \\
\hline$>$ one drug, $\mathrm{n}(\%)$ & $15(18 \%)$ & - & - \\
\hline \multicolumn{4}{|l|}{ Blood parameters } \\
\hline WBCs $\left[\times 10^{9} / \mathrm{L}\right]$ & $10 \pm 5$ & $8 \pm 3$ & 0.03 \\
\hline Lymphocyte (\%) & $16 \pm 5$ & $29 \pm 13$ & $<0.00$ \\
\hline Neutrophil (\%) & $77 \pm 10$ & $62 \pm 17$ & $<0.00$ \\
\hline Lymphocyte count $\left[\times 10^{9} / \mathrm{L}\right]$ & $1.4 \pm 0.5$ & $2.3 \pm 1$ & $<0.00$ \\
\hline Neutrophil count $\left[\times 10^{9} / \mathrm{L}\right]$ & $8 \pm 3$ & $5 \pm 2$ & $<0.00$ \\
\hline Neutrophil/lymphocyte & $7 \pm 0.9$ & $5 \pm 1$ & 0.22 \\
\hline Platelet/lymphocyte & $196 \pm 15$ & $200 \pm 33$ & 0.91 \\
\hline $\operatorname{RBC}\left[10^{6} / \mu \mathrm{L}\right]$ & $4.5 \pm 0.6$ & $4.6 \pm 0.6$ & 0.25 \\
\hline $\mathrm{Hb}[\mathrm{g} / \mathrm{dL}]$ & $12 \pm 2$ & $13 \pm 2$ & 0.31 \\
\hline MCV [fl] & $85 \pm 7$ & $87 \pm 60$ & 0.11 \\
\hline RDW $(\%)$ & $45 \pm 4$ & $44 \pm 4$ & 0.78 \\
\hline Platelet count $\left[\times 10^{9} / \mathrm{L}\right]$ & $251 \pm 50$ & $264 \pm 25$ & 0.57 \\
\hline PDW $(\%)$ & $13 \pm 3$ & $12 \pm 2$ & 0.01 \\
\hline PMV (fl) & $9 \pm 1$ & 9.1 & 0.13 \\
\hline \multicolumn{4}{|l|}{ In-hospital outcomes } \\
\hline In-hospital death, n (\%) & $13(19 \%)$ & $9(9 \%)$ & 0.15 \\
\hline Hospital stay [day] & $9 \pm 2$ & $3 \pm 1$ & $<0.00$ \\
\hline ICU stay [day] & $6 \pm 1$ & $3 \pm 1$ & $<0.00$ \\
\hline Lung injury & $42 \pm 22$ & $20 \pm 12$ & $<0.00$ \\
\hline Mechanical ventilation use, $\mathrm{n}(\%)$ & $26(31 \%)$ & $12(12 \%)$ & $<0.00$ \\
\hline
\end{tabular}

ARB — angiotensin receptor blocker; ACEI — angiotensin-converting enzyme inhibitor; BMI — body mass index; ICU — intensive care unit; MCV — mean cell volume; PDW — platelet distribution width; PMV — platelet mean volume; RDW — red blood cell distribution width; WBCs — white blood cells

have been reported that patients with underlying chronic metabolic disorders, such as diabetes, obe- sity and hypertension, can modulate the function of the innate and humoral immune systems leading to 
Table 2. Univariate analysis of angiotensin receptor blocker (ARBs) and angiotensin-converting enzyme inhibitor (ACEls) with in-hospital outcome

\begin{tabular}{|l|c|c|c|c|c|c|c|c|c|c|}
\hline & \multicolumn{2}{|c|}{ Death } & \multicolumn{2}{c|}{$\begin{array}{c}\text { Mechanical } \\
\text { ventilation use }\end{array}$} & \multicolumn{2}{c|}{$\begin{array}{c}\text { Length of ICU } \\
\text { stay }\end{array}$} & \multicolumn{2}{c|}{$\begin{array}{c}\text { Length of hospital } \\
\text { stay }\end{array}$} & \multicolumn{3}{c|}{ Lung injury } \\
\hline ARBs & $0.6(0.1-4)$ & 0.67 & $1(0.3-4)$ & 0.78 & $\begin{array}{c}0.2 \\
(-12-2)\end{array}$ & 0.18 & $\begin{array}{c}0.3 \\
(-17-2)\end{array}$ & 0.13 & $\begin{array}{c}0.1 \\
(-22-8)\end{array}$ & 0.34 \\
\hline ACEls & $0.4(0.0-5)$ & 0.55 & $1(0.2-6)$ & 0.70 & $\begin{array}{c}0.1 \\
(-12-4)\end{array}$ & 0.33 & $\begin{array}{c}0.2 \\
(-18-3)\end{array}$ & 0.17 & $\begin{array}{c}0.0 \\
(-16-20)\end{array}$ & 0.81 \\
\hline
\end{tabular}

ICU - intensive care unit

Table 3. Multivariate regression***

\begin{tabular}{|c|c|c|}
\hline \multicolumn{3}{|l|}{ Lung injury } \\
\hline Predictor & $\mathrm{OR}(\mathrm{Cl})$ & $p$ value \\
\hline Old age & $0.6(0.5-2)$ & $<0.00$ \\
\hline Fever on admission & $0.3(0.2-1.8)$ & $<0.00$ \\
\hline Low lymphocyte \% & $0.3(0.2-1.2)$ & $<0.00$ \\
\hline \multicolumn{3}{|l|}{ Length of hospital stay } \\
\hline & OR (CI) & p value \\
\hline Old age & $0.4(0.1-0.7)$ & $<0.00$ \\
\hline Low lymphocyte \% & $0.3(0.1-0.7)$ & 0.01 \\
\hline High neutrophil count & $0.3(0.2-2)$ & 0.02 \\
\hline \multicolumn{3}{|l|}{ Length of ICU stay } \\
\hline & $\mathrm{OR}$ (CI) & $p$ value \\
\hline Low lymphocytes \% & $0.7(0.6-0.9)$ & $<0.00$ \\
\hline Old age & $1.2(1-1.4)$ & 0.01 \\
\hline Fatigue on admission & $2(1-4)$ & 0.04 \\
\hline \multicolumn{3}{|c|}{ Mechanical ventilation use } \\
\hline & $\mathrm{OR}$ (CI) & $\mathrm{p}$ value \\
\hline Low lymphocyte \% & $0.7(0.6-1)$ & $<0.00$ \\
\hline Old age & $1.1(1-1.2)$ & 0.01 \\
\hline Fatigue on admission & $2(1.7-4)$ & 0.02 \\
\hline \multicolumn{3}{|l|}{ In-hospital death } \\
\hline & $\mathrm{OR}$ (CI) & $\mathrm{p}$ value \\
\hline High neutrophil \% & $1.2(1-1.5)$ & 0.01 \\
\hline Old age & $1.1(1-1.2)$ & 0.03 \\
\hline
\end{tabular}

*significant variables, including baseline blood parameters, comorbidities and clinical symptoms with $p$ value $<0.05$ in the univariate logistic regression model were entered as predictors in the final multivariate regression model; ** only variables significant with $\mathrm{p}$ value $<0.05$ are displayed in the table; $\mathrm{OR}(\mathrm{Cl})$ - odd ratio (confidence interval)

cytokines imbalance and chronic low-grade systemic inflammatory phenotype. As such, this chronic lowgrade systemic inflammation in COVID-19 patients who have underlying chronic diseases could promote systemic inflammatory response when SARS-CoV-2 infected $[8,9,13]$.

Another major mechanism by which COVID-19 can lead to adverse outcome is via virus binding to ACE2 receptors, which is required for virus entry into target cells in the cardiovascular system and lungs [2, 14]. Patients with hypertension, diabetes and coronary artery disease are the most consumers of ACEIs and ARBs. There is evidence from experimental studies that inhibition of ACE2 production by negative feedback from the use of ACEIs and $A R B s$ for treatment of hypertension and other cardiovascular diseases increases the expression of the ACE2 receptors particularly in the cardiac tissues, thus increasing the availability of target molecules for SARS-CoV-2 $[2,15]$. However, the upregulation in ACE2 following ARB or ACEI use is observed after high dose administration of these drugs in animals and not in doses commonly used in humans. Also, this upregulation has been documented mainly in cardiac tissues and not in the lungs [16].

In our study, ARBs and ACEIs showed no significant association with adverse in-hospital outcome, although about $70 \%$ of patients with hypertension enrolled in the study were on ACEIs or ARBs prior to hospital admission. In the literature, the role of $\mathrm{ARBs}$ and ACEIs in the pathogenesis and severity of COVID-19 infection is obscure and controversial [8]. In the early phase of COVID-19 infection, there has been concern regarding the potential harmful role of ACEIs and ARBs based on previous animal studies showing that these drugs could alter tissue expression of ACE2 leading to enhance susceptibility to viral host cell entry and propagation [17]. On the other hand, no effect of ACEIs or ARBs on ACE2 activity was found in recent reports $[14,18]$. Consistent with our results, Guo et al. reported that ARB and ACEI use was not associated with increased patients' mortality rate, although more patients were using ACEI and ARB medications prior to COVID-19 infection [19]. Also, use of ACEI or ARB among hospitalized COVID-19 patients with hypertension was associated with lower risk of all-cause mortality compared with ACEI/ARB non-users $[8,20]$.

Regarding blood parameters' role in COVID-19 patients with hypertension, low lymphocyte count or percentage and high neutrophil count or percentage may be considered as a cardinal finding in COVID-19 infection with prognostic implication in determining disease severity and progression [21]. 
High neutrophil count reflects the intensity of inflammatory response during COVID-19 pneumonia, while low lymphocyte count reflects the damage of immune system and may perpetuate a harmful inflammatory status [22]. Chronic cardiovascular disease, such as hypertension, may influence neutrophils count and function [23]. The predictive role of lymphocyte and neutrophil counts in assessing the severity of COVID-19 pneumonia is consistent with previous reports that patients infected with SARS-CoV-2 had a high neutrophil count and a low lymphocyte count during the severe phase [24, 25]. In line with a previous report, $\mathrm{Zhu} Z$ et al. found that high level of peripheral blood cytokine IL-6, significant increase in neutrophil count, significant decrease in lymphocyte percentage, and hypertension were independent risk factors for assessing the severity of COVID-19 [22].

The present study has several limitations. The sample size was relatively small recruited from single hospital. The design of the study was retrospective, thus residual confounding might exist.

\section{Conclusion}

COVID-19 pneumonia patients with hypertension were likely to have adverse in-hospital outcomes compared to COVID-19 pneumonia patients without hypertension. ARBs and ACEIs showed no significant association with adverse in-hospital outcomes. Old age, low lymphocyte percentage and high neutrophil percentage on admission were independent predictors for increased risk of in-hospital mortality and morbidity among COVID-19 pneumonia patients with hypertension.

\section{Funding}

There were no external funding sources for this study.

\section{Conflict of interest}

The authors declare that they have no conflict of interest.

\section{References}

1. Renu K, Prasanna PL, Valsala Gopalakrishnan A. Coronaviruses pathogenesis, comorbidities and multi-organ damage - A review. Life Sci. 2020; 255: 117839, doi: 10.1016/j.lfs.2020.117839, indexed in Pubmed: 32450165.

2. Babadaei MM, Hasan A, Bloukh SH, et al. The expression level of angiotensin-converting enzyme 2 determines the severity of COVID-19: lung and heart tissue as targets. J Biomol Struct Dyn. 2020 [Epub ahead of print]: 1-7, doi: 10.1080/07391102.2020 .1767211 , indexed in Pubmed: 32397951.
3. Landi F, Barillaro C, Bellieni A, et al. The New Challenge of Geriatrics: Saving Frail Older People from the SARS-COV-2 Pandemic Infection. J Nutr Health Aging. 2020; 24(5): 466-470, doi: 10.1007/s12603-020-1356-x, indexed in Pubmed: 32346682.

4. Wu F, Zhao Su, Yu B, et al. A new coronavirus associated with human respiratory disease in China. Nature. 2020; 579(7798): 265-269, doi: 10.1038/s41586-020-2008-3, indexed in Pubmed: 32015508.

5. Morra ME, Van Thanh Le, Kamel MG, et al. Clinical outcomes of current medical approaches for Middle East respiratory syndrome: A systematic review and meta-analysis. Rev Med Virol. 2018; 28(3): e1977, doi: 10.1002/rmv.1977, indexed in Pubmed: 29664167.

6. Matsuyama R, Nishiura H, Kutsuna S, et al. Clinical determinants of the severity of Middle East respiratory syndrome (MERS): a systematic review and meta-analysis. BMC Public Health. 2016; 16(1): 1203, doi: 10.1186/s12889-016-3881-4, indexed in Pubmed: 27899100.

7. Huang C, Wang Y, Li X, et al. Clinical features of patients infected with 2019 novel coronavirus in Wuhan, China. Lancet. 2020; 395(10223): 497-506, doi: 10.1016/S0140-6736(20)30183-5, indexed in Pubmed: 31986264.

8. Zhao M, Wang M, Zhang J, et al. Advances in the relationship between coronavirus infection and cardiovascular diseases. Biomed Pharmacother. 2020; 127: 110230, doi: 10.1016/j. biopha.2020.110230, indexed in Pubmed: 32428835.

9. Huang S, Wang J, Liu F, et al. COVID-19 patients with hypertension have more severe disease: a multicenter retrospective observational study. Hypertens Res. 2020; 43(8): 824-831, doi: 10.1038/ s41440-020-0485-2, indexed in Pubmed: 32483311.

10. Park JE, Jung S, Kim A, et al. MERS transmission and risk factors: a systematic review. BMC Public Health. 2018; 18(1): 574, doi: 10.1186/s12889-018-5484-8, indexed in Pubmed: 29716568.

11. Matsuyama R, Nishiura H, Kutsuna S, et al. Clinical determinants of the severity of Middle East respiratory syndrome (MERS): a systematic review and meta-analysis. BMC Public Health. 2016; 16(1): 1203, doi: 10.1186/s12889-016-3881-4, indexed in Pubmed: 27899100.

12. Jin Y, Yang H, Ji W, et al. Virology, Epidemiology, Pathogenesis, and Control of COVID-19. Viruses. 2020; 12(4), doi: 10.3390/ v12040372, indexed in Pubmed: 32230900.

13. Zhao K, Li R, Wu X, et al. Clinical features in 52 patients with COVID-19 who have increased leukocyte count: a retrospective analysis. Eur J Clin Microbiol Infect Dis. 2020; 39(12): 2279-2287, doi: 10.1007/s10096-020-03976-8, indexed in Pubmed: 32651736.

14. Gebhard C, Regitz-Zagrosek V, Neuhauser HK, et al. Impact of sex and gender on COVID-19 outcomes in Europe. Biol Sex Differ. 2020; 11(1): 29, doi: 10.1186/s13293-020-00304-9, indexed in Pubmed: 32450906.

15. Bosso M, Thanaraj TA, Abu-Farha M, et al. The Two Faces of ACE2: The Role of ACE2 Receptor and Its Polymorphisms in Hypertension and COVID-19. Mol Ther Methods Clin Dev. 2020; 18: 321-327, doi: 10.1016/j.omtm.2020.06.017, indexed in Pubmed: 32665962.

16. Vlachakis PK, Tentolouris A, Tousoulis D, et al. Current data on the cardiovascular effects of COVID-19. Hellenic J Cardiol. 2020; 61(1): 46-48, doi: 10.1016/j.hjc.2020.04.001, indexed in Pubmed: 32315757.

17. Shibata S, Arima H, Asayama K, et al. Hypertension and related diseases in the era of COVID-19: a report from the Japanese Society of Hypertension Task Force on COVID-19. Hypertens Res. 2020; 43(10): 1028-1046, doi: 10.1038/s41440-020-05150, indexed in Pubmed: 32737423.

18. Zhou Y, Yang Q, Chi J, et al. Obesity and diabetes as high-risk factors for severe coronavirus disease 2019 (Covid-19). Diabetes Metab Res Rev. 2021; 37(2): e3377-56, doi: 10.1002/dmrr.3377, indexed in Pubmed: 32588943. 
19. Guo T, Fan Y, Chen M, et al. Cardiovascular Implications of Fatal Outcomes of Patients With Coronavirus Disease 2019 (COVID-19). JAMA Cardiol. 2020; 5(7): 811-818, doi: 10.1001/ jamacardio.2020.1017, indexed in Pubmed: 32219356.

20. Zhang P, Zhu L, Cai J, et al. Association of Inpatient Use of Angiotensin-Converting Enzyme Inhibitors and Angiotensin II Receptor Blockers With Mortality Among Patients With Hypertension Hospitalized With COVID-19. Circ Res. 2020; 126(12): 1671-1681, doi: 10.1161/CIRCRESAHA.120.317134, indexed in Pubmed: 32302265.

21. Terpos E, Ntanasis-Stathopoulos I, Elalamy I, et al. Hematological findings and complications of COVID-19. Am J Hematol. 2020; 95(7): 834-847, doi: 10.1002/ajh.25829, indexed in Pubmed: 32282949

22. Zhu Z, Cai T, Fan L, et al. Clinical value of immune-inflammatory parameters to assess the severity of coronavirus disease 2019. Int
J Infect Dis. 2020; 95: 332-339, doi: 10.1016/j.ijid.2020.04.041, indexed in Pubmed: 32334118.

23. Qin C, Zhou L, Hu Z, et al. Dysregulation of Immune Response in Patients With Coronavirus 2019 (COVID-19) in Wuhan, China. Clin Infect Dis. 2020; 71(15): 762-768, doi: 10.1093/ cid/ciaa248, indexed in Pubmed: 32161940.

24. Wang D, Hu Bo, Hu C, et al. Clinical Characteristics of 138 Hospitalized Patients With 2019 Novel Coronavirus-Infected Pneumonia in Wuhan, China. JAMA. 2020; 323(11): 10611069, doi: 10.1001/jama.2020.1585, indexed in Pubmed: 32031570.

25. Yan X, Li F, Wang X, et al. Neutrophil to lymphocyte ratio as prognostic and predictive factor in patients with coronavirus disease 2019: A retrospective cross-sectional study. J Med Virol. 2020; 92(11): 2573-2581, doi: 10.1002/jmv.26061, indexed in Pubmed: 32458459 . 